\title{
A IMPORTÂNCIA DE NARRAR A MEMÓRIA DO VELHO OPRIMIDO NO CAPITALISMO
}

\author{
LA IMPORTANCIA DE NARRAR LA MEMORIA \\ DEL VIEJO OPRIMIDO EN EL CAPITALISMO
}
THE IMPORTANCE OF NARRATING THE MEMORY
OF THE OPRESSED ELDER IN CAPITALISM

\author{
Larissa Leão de Castro ${ }^{1}$ \\ ${ }^{1}$ Universidade de Brasília, Brasília/DF, Brasil
}

\begin{abstract}
RESUMO: Este estudo objetivou compreender a importância de narrar e transmitir experiência a partir da memória do velho e do lugar de pária que lhe é destinado no modo de produção do capitalismo. Parte de estudos realizados pela psicóloga social Ecléa Bosi e por Benjamin. São discutidos dois elementos presentes nas experiências relatadas pela autora e que estão presentes no conceito de história já elaborado por Benjamin: a importância da rememoração e da redenção messiânica. A relevância de narrar as experiências diz respeito ao que se apresenta predominantemente nas memórias colhidas: a transmissão das possibilidades não realizadas. Analisa-se como a forma de trabalho flexível do capitalismo violenta a possibilidade de construção da memória de si na sua vinculação com a memória do outro ao impor aos sujeitos o desenraizamento e seu efeito desagregador da memória. Por fim, discute-se a urgente necessidade de transformação das condições que geram opressão dos velhos trabalhadores.
\end{abstract}

PALAVRAS-CHAVE: Experiência; Memória dos velhos; Capitalismo e Desenraizamento; Desagregação; Exclusão.

RESUMEN: Este estudio tuvo como objetivo comprender la importancia de narrar y transmitir experiencia a partir de la memoria del viejo y del lugar de paria que le es destinado en el modo de producción del capitalismo. Parte de los estudios realizados por la psicóloga social Ecléa Bosi y Walter Benjamin. Se discuten dos elementos presentes en las experiencias relatadas por la autora y que están presentes en el concepto de historia ya elaborado por Benjamin: la importancia de la evocación y de la redención mesiánica. La relevancia de narrar las experiencias se refiere a lo que se presenta predominantemente en las memorias cosechadas: la transmisión de las posibilidades no realizadas. Se analiza cómo la forma de trabajo flexible del capitalismo violenta la posibilidad de construcción de la memoria de sí en su vinculación con la memoria del otro al imponer a los sujetos el desarraigo y su efecto disgregador de la memoria. Por último, se discute la urgente necesidad de transformación de las condiciones que generan opresión de los viejos trabajadores.

PALABRAS CLAVE: Experiencia; Memoria de los viejos; Capitalismo y Desarraigo; Disgregación; Exclusión.

ABSTRACT: This study aimed to understand the importance of narrating and transmitting experience from the memory of the elder and the place of pariah destined to them in capitalism's mode of production. It has as reference studies carried out by the social psychologist Ecléa Bosi and by Walter Benjamin. Two elements present in the experiences reported by Bosi - which are present in the concept of history already elaborated by Benjamin -, are discussed: the importance of the remembrance and the messianic redemption. The relevance of narrating experiences relates to what is predominantly presented in the collected memories: the transmission of unrealized possibilities. It is analyzed how capitalism's flexible working form violates the possibility of constructing the memory of oneself in its connection with the memory of the other by imposing on people the uprooting and its disintegrating effect of memory. Finally, it discusses the urgent need to transform the conditions that generate oppression of the old workers.

KEYWORDS: Experience; Memory of the elders; Capitalism and uprooting; Disintegration; Exclusion. 


\section{Introdução}

Não existem, has vozes a que agora damos ouvidos, ecos de vozes que emudeceram? ... Se assim é, foi-nos concedida, como a cada geração anterior à nossa, uma frágil força messiânica para a qual o passado dirige um apelo. Esse apelo não pode ser rejeitado impunemente. O materialista histórico sabe disso. (Benjamin, 2012a, p. 242)

Ecleá Bosi, ao findar o livro fruto do estudo da memória de velhos retoma o conselho de um deles: "tolerância para com os velhos, tolerância mesmo para com aqueles que se transviaram na juventude: 'Eles também trabalharam'” (Bosi, 1994, p. 481). Ao narrar as experiências colhidas pelas entrevistas com oito velhos, a autora ressalta a importância que Walter Benjamin (2012b) já deu à noção de conselho presente na arte de narrar. A partir das experiências narradas pela autora, essa importância está no senso prático da necessidade de uma aprendizagem (norma de vida) e ação transformadora diante da condição de opressão que a velhice vive no desenvolvimento do capitalismo brasileiro. ${ }^{1}$

Todas essas diferentes histórias terminam num destino comum de solidão, do lugar de párias, excluídos e marginalizados pela sociedade; ou seja, se entrelaçam num elemento comum de pertencimento à classe dos oprimidos. ${ }^{2}$ Esse conselho indica o respeito que se deve ter pelos que trabalharam; indica a opção de narrar a história a partir da experiência dos trabalhadores derrotados, fundando o que conceitua por "comunidade de destino", que nos une a todos e a cada um no destino da velhice - o qual nessa particularidade histórica é o da exclusão-, e que "Significa sofrer de maneira irreversível, sem possibilidade de retorno à antiga condição, o destino dos sujeitos observados.” (Bosi, 1994, p. 38).

Ao dar ouvidos a essas vozes que emudeceram, há um apelo de superação da opressão vivida pelas minorias, apelo este ainda maior no que diz respeito à opressão vivida pelos velhos na sociedade atual, o que se nota a partir da análise da autora de que, dentre os grupos minoritários, o velho não tem armas para combater pelos seus direitos: "Nós é que temos de lutar por ele" (Bosi, 1994, p. 81).

Essa tarefa de impedir a continuidade da opressão é atribuída à ação ativa das gerações do presente, tal como afirmara Benjamin, e Michael Löwy ressalta ao reafirmar: "a importância da exigência que vem do passado: não há redenção para a geração presente se ela fizer pouco caso da reivindicação (Anspruch) das vítimas da história” (Löwy, 2005, p. 52).

Ao entrar em contato com o vínculo presente entre as experiências dos velhos trabalhadores oprimidos narradas pela autora, notam-se dois elementos essenciais presentes no conceito de história já elaborado por Benjamin: a importância da rememoração e da redenção messiânica. Impõe-se a necessidade de rememoração, bem como de reparação do abandono pela transformação das condições que geram a opressão do passado e do presente do velho que vive numa condição paradoxal de dependência social e, ao mesmo tempo, de exclusão, silenciamento e solidão.

Percorrida essa breve introdução, esse artigo teórico se propõe a discutir esses dois elementos presentes na obra sobre a memória dos velhos, da psicóloga social Ecléa Bosi: a importância da rememoração e da transformação das condições que geram opressão dos velhos trabalhadores. 


\section{A alta função da lembrança dos velhos: a transmissão das possibilidades não realizadas}

A velhice articula um caráter universal, pois é um destino do sujeito, mas também particular, pois esse período histórico do capitalismo vive as perdas biológicas do homem de forma diferente dos períodos anteriores, com a característica especifica da depreciação e exclusão de quem passa por elas. Por isso a autora ressalta que a velhice é uma categoria social a qual é atacada no capitalismo pelos malefícios da sociedade industrial e do consumo em todas as suas dimensões. (Bosi, 1994, p. 77)

Em contraste, a autora resgata o lugar privilegiado dos velhos em outras sociedades, como naquelas em que ocupa o lugar do ancião, uma vez que ele pode exercer importância primordial no processo de socialização e construção da memória do adulto e da criança, fazendo-os reviver o que foi perdido nos vínculos afetivos; refletir sobre as tradições, sobre o que se mantém nas ações, mas não se reconhece ainda como continuidade do passado e/ ou das pessoas que não estão mais presentes; refletir sobre as lições tiradas de suas experiências (Bosi, 1994).

Considerando-se o lugar de opressão vivido pelo velho no modo de produção do capitalismo, podemos ressaltar sua importância, sobretudo na transmissão das possibilidades não realizadas. Essa transmissão está indissoluvelmente ligada à necessidade de ação ativa das gerações do presente para realizar possibilidades que foram interrompidas e que, no entanto, ficaram latentes. Há, por exemplo, um sentido importante no trabalho narrativo do velho de reconstrução das lembranças da infância, como é analisado pela autora:

Se examinarmos criticamente a meninice podemos encontrar nela aspirações truncadas, injustiças, prepotência, a hostilidade habitual contra os fracos. Poucos de nós puderam ver florescer seus talentos, cumprir sua vocação mais verdadeira. Comparamos acaso nossos ideais antigos com os presentes? Examinamos as raízes desse desengano progressivo das relações sociais?

A criança sofre, o adolescente sofre. De onde nos vêm, então, a saudade e a ternura pelos anos juvenis? Talvez porque nossa fraqueza fosse uma força latente e em nós houvesse o germe de uma plenitude a se realizar.” (Bosi, 1994, p. 83)

Esse é um sentido encontrado pela autora, ao refletir sobre a velhice em sua alta função da lembrança. Ela compreende que o trabalho de rememorar não se confunde com a reprodução de imagens ou pensamentos, mas exige nesse processo o que chama de uma reaparição e sua capacidade de distinguir o presente do passado. Nesse movimento de troca de experiências entre o velho e as gerações seguintes, nota-se a importância de uma experiência de abertura para as diferentes possibilidades de existir, tanto com relação a um dos possíveis do passado quanto com relação ao que se efetiva ou aos possíveis do presente. Nesse sentido, Jeanne Marie Gagnebin (2012) já notara a relação entre a noção de história aberta de Walter Benjamin e esse efeito humanizador advindo da troca da experiência. Podemos acrescentar que em ambos há: 
A mesma preocupação de salvar o passado no presente graças à percepção de uma semelhança que os transforma a ambos: transforma o passado porque este assume uma forma nova, que poderia ter desaparecido no esquecimento; transforma o presente porque este se revela como sendo a realização possível dessa promessa anterior, que poderia ter-se perdido para sempre, que ainda pode se perder se não a descobrirmos, inscrita nas linhas do atual. (Gagnebin, 2012, p. 16)

Cabe analisar que o trabalho de rememoração, pela via da reaparição das experiências, está intimamente relacionado com o efeito e/ou abertura para a possibilidade da transformação da realidade. Sigmund Freud (1914/1996), por outros caminhos, no tex to "Repetir, Recordar e Elaborar", também ressalta esse efeito e sua importância num tratamento na psicanálise, indicando a necessidade requerida de que o sujeito pare de reproduzir puramente os seus sintomas, numa necessidade de ação motora, e que comece a falar sobre ele, sobre o que o leva a agir assim. Ou seja, há a indicação da necessidade da fala - repetir na espera psíquica, para então se iniciar um processo de elaboração; o que inclui entrar em contato com as motivações inconscientes para as ações, que frequentemente remetem ao vínculo entre o passado e o presente que nos constitui enquanto sujeitos.

Assim, por diferentes caminhos, nota-se nesse procedimento uma epistemologia dialética que não naturaliza os fenômenos e não busca a mera adaptação dos indivíduos à sociedade, mas os pensa a partir do critério de uma análise histórica de sua constituição, vislumbrando a possibilidade de transformação do presente, uma vez que ele também é histórico, assim como os sofrimentos que dele advém.

Note-se que em ambos os casos a importância primordial está no poder da fala e seus efeitos. Ecléa Bosi retoma a afirmação dos psicólogos sociais da memória de que só há memória se ela pode ser evocada e significada (Bosi, 1994). Contudo, numa sociedade de consumo que cultua a juventude, a presentificação da vida e deprecia a velhice; a troca de experiência entre os velhos e as gerações mais novas se torna rara, fundando gerações desmemoriadas e aderentes ao presente. Nesse sentido a autora afirma:

Quando a sociedade esvazia seu tempo de experiências significativas, empurrando-o para a margem, a lembrança de tempos melhores se converte num sucedâneo da vida. E a vida atual só parece significar se ela recolher de outra época o alento. $\mathrm{O}$ vínculo com outra época, a consciência de ter suportado, compreendido muita coisa, traz para o ancião alegria e uma ocasião de mostrar sua competência. Sua vida ganha uma finalidade se encontrar ouvidos atentos, ressonância. (Bosi, 1994, p. 82)

Contudo, no capitalismo, o velho - que ocupava a função de ancião-, se vê privado de sua função de narrar. A autora analisa que há um sentimento coletivo gerado por esse momento histórico de aborrecimento diante de tantas experiências a partir das quais o velho quer aconselhar. Em seu lugar, há a valorização da transformação dos velhos para se adequar aos hábitos e valores da juventude, assim como à presentificação (Bosi, 1994). 
A autora nota que a decadência da arte de contar histórias produz a decadência da troca de experiências. Esta, por sua vez, se deve em grande medida ao desenvolvimento da técnica e ao triunfo da informação de imprensa no capitalismo, em detrimento da busca da sabedoria ou de conselhos presentes no campo da narrativa. Benjamin (2012b) atribui essa nova forma de miséria ao desenvolvimento da técnica que não permite que a experiência nos vincule culturalmente, tornando-nos pobres de cultura, mas sobretudo "em experiências da humanidade em geral" (Benjamin, 2012b, p. 125). O autor dirá que uma nova forma de barbárie aparece nesse processo histórico. Tem o efeito dos sujeitos aderirem cegamente ao presente, naturalizando a violência e o mal que carrega, sem vislumbrar outras possibilidades para a realidade.

Nesse sentido, os meios de comunicação de massa constituem uma das mediações que privam a velhice de sua função de narrar, assim como privam a força de coesão dos valores transmitidos para as crianças no grupo da família. Essa força de união a partir da transmissão da experiência dava ao grupo familiar uma certa constância e permitia se defender contra a rapidez das mudanças e contra a fluidez dos novos valores presentes no mercado. Nota-se essa presença na narrativa de D. Brites, quando narra sobre a mudança ocorrida: "Minha casa tinha portão fechado, nós vivíamos ali dentro e entrava só quem nossa mãe achava que podia entrar, que devia entrar. Agora não, você está fechada dentro de casa e cata pelo ar tudo quanto é anúncio. Você não tem mais uma casa fechada” (Bosi, 1994, p. 423).

Enquanto a narração de uma experiência ou de uma crônica envolve a ausência de explicação e ao mesmo tempo a possibilidade de tirar alguma lição dela, a informação transmitida pelos meios de comunicação de massa não permite desvelar verdades profundas que servem para a vida, nem mesmo a elaboração e a sedimentação da informação na memória (Bosi, 1994). Nesse sentido:

A narração exemplar foi substituída pela informação de imprensa, que não é pesada e medida pelo bom senso do leitor. Assim, a união de uma cantora com um esportista ocupa mais espaço que uma revolução. A informação pretende ser diferente das narrações dos antigos: atribui-se foros de verdade quando é tão inverificável quanto a lenda. Ela não toca no maravilhoso, sequer no plausível. A arte de narrar vai decaindo com o triunfo da informação. Ingurgitada de explicações, não permite que o receptor tire dela alguma lição. Os nexos psicológicos entre os eventos que a narração omite ficam por conta do ouvinte, que poderá reproduzi-la à sua vontade; daí o narrado possuir uma amplitude de informações que falta à informação. (Bosi, 1994, pp. 85-86)

E se por um lado decai a arte de trocar experiências, por outro lado decai a arte de escutar. As pessoas se tornam refratárias à dimensão do conselho - sentido como antiquado -; refratárias às atividades que demandam tempo e paciência (Bosi, 1994). Empobrecemos-nos assim dos efeitos da troca de experiência, de rememoração e da esperança, bases da liberdade.

Afirmar isso não se confunde com um movimento irracional e saudosista do passado que não discerne a riqueza do que se perdeu do mal que o passado carrega. Significa indicar elementos precisos da privação, sobretudo do velho, de sua função de narrar, assim como os elementos do empobrecimento da experiência e de sua transmissão na particularidade histórica da sociedade de consumo, que deve ser superada para a superação dessa forma de opressão. 
Compreendendo a importância de narrar, a autora analisa que o narrador trabalha a matéria-prima da experiência, penetrando na natureza dos fenômenos e alcançando suas verdades:

Tira segredos e lições que estavam dentro das coisas, faz uma sopa deliciosa das pedras do chão, como no conto da Carochinha. A arte de narrar é uma relação de alma, olho e mão: assim transforma o narrador sua matéria, a vida humana. (Bosi, 1994, p. 91)

Nesse período histórico, as experiências dos velhos narradas por Eclea Bosi nos mostram não só a privação da função de narrar, da rememoração e da esperança, a que está submetido. Nas condições que geram a exclusão e privação que o velho está destinado na sociedade capitalista, quando ele consegue transmitir experiência em sua função de narrar, identifica-se primordialmente a transmissão das possibilidades não realizadas: "Seu talento de narrar lhe vem da experiência; sua lição, ele extraiu da própria dor; sua dignidade é a de contá-la até o fim, sem medo" (Bosi, 1994, p. 91). E uma das determinações fundamentais para que compreendamos a interrupção dessas possibilidades é a mediação do trabalho expressa na substância de suas vidas e de suas memórias.

\section{Trabalho e desenraizamento: a condição desagregadora da memória}

A substância social da memória está intimamente relacionada com as condições de trabalho existentes. Atendendo tanto à dimensão do trabalho no tempo subjetivo do entrevistado quanto a sua realidade objetiva no capitalismo, Bosi (1994) identifica que a fusão do trabalho com a substância da vida se dá em todos entrevistados. Contudo, essa mediação na sociedade capitalista de consumo se apresenta como central com a característica da privação da constituição da memória de si pela memória do outro, o que formaria uma unidade na constituição dos sujeitos, e que teria como uma das características a resistência à mudança.

A autora ressalta o elemento fundamental de construção da memória que se dá a partir da memória de um outro e/ou da memória grupal, tal como Goethe expressara: "Quando queremos nos recordar do que nos aconteceu nos primeiros tempos de nossa infância, confundimos seguidamente o que escutamos dos outros com nossas próprias lembranças" (Goethe, 1986, citado por Bosi, 1994, p. 435). Nesse sentido, a memória de si passa a ser constituída por processos de internalização da memória do outro por meio de processos de identificação e vinculação a ele, construindo-se então uma memória e uma identidade grupal.

Com relação a esse elemento, na evocação de lembranças pelos diferentes sujeitos nos deparamos com os destaques de alguns elementos ou alterações de outros. Estamos lidando nessas seleções com a expressão da subjetividade e com a elaboração própria acerca da memória coletiva; o que expressa os valores, ideologias, estereótipos do sujeito que se coloca na relação com o outro. Dito de outro modo, Ecléa retoma uma noção desenvolvida por Halbwachs de que "cada memória individual é um ponto de vista sobre a memória coletiva” (Bosi, 1994, p. 413).

Para a autora "O grupo é o suporte da memória se nos identificamos com ele e fazemos nosso seu passado" (Bosi, 1994, p. 414). Narrar atos e histórias de entes queridos da 
família funciona como símbolo que transmite uma lição e inspiração para seus membros, construindo uma memória coletiva que unifica a família em torno de símbolos compartilhados, dando aos sujeitos a possibilidade de construção da memória grupal e o sentimento de continuidade na história. Conforme a autora:

Há episódios antigos que todos gostam de repetir, pois a atuação de um parente parece definir a natureza íntima da família, fica sendo uma atitude-símbolo. Reconstituir o episódio é transmitir a memória do grupo e inspirar os menores. Podemos reconstruir um período a partir desse episódio. Tocamos sem querer a história, nos quadros sociais do passado: moradias, roupas, costumes, linguagem, sentimentos. (Bosi, 1994, p. 424)

Contudo, o capitalismo caracterizado pela forma de trabalho flexível, predominante até os dias de hoje, violenta a possibilidade de construção da memória de si pela memória do outro, tendo em vista que impõe aos sujeitos o desenraizamento, que gera o efeito desagregador da memória. Nesse sentido:

As jornadas operárias em turnos alternados semanais afetam a coerência da vida da família, roubam o passado e o futuro. Impedem os projetos e a sedimentação das lembranças, lançam o trabalhador num tempo mecânico, homogêneo, onde qualquer ponto pode ser o de origem, onde não há marcos de apoio. (Bosi, 1994, p. 417)

O velho ritmo da alimentação, do sono, dos encontros, dos vínculos, da rememoração e da construção da memória e da transmissão da experiência é violentado. Sendo assim, estamos em condições de compreender a diferenciação entre memória e ação, resgatada por Bosi (1994), ao constatar nas memórias colhidas a verdade de que quanto mais trabalho nesse modo de produção que exige o desenraizamento, mais difícil se torna o espaço para abrir-se para a rememoração - o que seria fundamental para a solidificação da memória; assim como se torna mais difícil a disponibilidade para narrar o passado.

É nesse contexto que a autora percebe, nas experiências colhidas, a evocação ao menos das perdas e do valor inestimável das pessoas amadas que se foram. As lembranças das pessoas do passado fazem com que os velhos, mesmo cansados da luta, evoquem a saudade dos amigos insubstituíveis. Ao se deparar com essas memórias, a autora pergunta: "Por que essa tendência à exemplaridade das figuras evocadas? Se, de um lado, há o processo de estereotipia, de outro as restrições e empobrecimento que pesam sobre a velhice tornam inestimável o que se perdeu” (Bosi, 1994, p. 431).

Pode-se dizer que o destino trágico de exclusão dos velhos nessa sociedade é o que insiste em ser evocado nas lembranças dos velhos. Eles foram interrompidos em suas possibilidades de vida pelas condições precárias de trabalho, assim como seus pares, relembrados com comoção por seu destino trágico: "Como o sr. Ariosto, o sr. Amadeu comove-se com as lides do alfaiate que trabalhava catorze, quinze horas por dia e que faleceu em 1925 de uma úlcera no estômago” (Bosi, 1994, p. 429).

A violenta privação imposta ao destino dos velhos é tamanha na atual sociedade capitalista que eles, já destituídos do lugar de sujeitos, buscam indicar na memória do trabalho a justificação de suas vidas: 
Durante a velhice deveríamos estar ainda engajados em causas que nos transcendem, que não envelhecem, e que dão significado a nossos gestos cotidianos. Talvez seja esse um remédio contra os danos do tempo. Mas pondera Simone de Beauvoir, se o trabalhador aposentado se desespera com a falta de sentido da vida presente, é porque em todo o tempo o sentido de sua vida lhe foi roubado. Esgotada sua força de trabalho, sente-se um pária, e é comum que o escutemos agradecendo sua aposentadoria como um favor ou esmola. (Bosi, 1994, p. 80)

Quando não são interrompidos pelo destino da morte - decorrente direta ou indiretamente de um trabalho extenuante -, frequentemente a estruturação do modo de produção do capitalismo flexível e sua necessidade de desenraizamento marca a biografia dessas histórias de vida, obrigando-os ao destino da solidão e exclusão. Esse é o destino relatado pelo sr. Abel:
Afastado de todos os que estimou, alijado do trabalho, internado num hospital psi- quiátrico e agora num asilo, ele pergunta: "Voltar para casa? Não, eu não tenho mais condiçães de viver lá. Não conheço mais ninguém. Eu chamo este asilo de gaiolão de ouro. Gaiolão de porta aberta. Mas, fugir para quê?? Para onde eu vou?”(Bosi, 1994, p. 433)

Essas experiências narradas pelos velhos nos mostram um destino de exclusão reservado aos que tiveram roubadas suas possibilidades de vida e de construção de um sentido para ela; de sentidos que tinha ou poderia ter tido.

O desenraizamento dos pobres forçado pelo trabalho flexível e sua precarização, pelo trabalho explorado, gratuito ou mal-pago, com a desvalorização real do salário; somado às perdas que o tempo impõe (fisiológicas, da capacidade produtiva); faz com que os velhos fiquem impedidos não só de manter os vínculos afetivos mais fortes com as suas famílias e pessoas que ainda estão vivas, mas também obstaculariza as possibilidades de recordar, predominantemente estimulada quando se há a possibilidade de transmitir experiência.

Como já analisara Benjamin (2012c), a transformação desta realidade de violência, privação e exclusão não se dará pela vinda de um messias, mas sim da ação ativa das gerações. É necessário romper a desumanização presente na atitude contemplativa da realidade, vez que a violência e exclusão do presente demandam a urgência de um engajamento ativo para impedir a continuidade do horror (Löwy, 2005). E esse processo não se dará sem o que conceitua por rememoração das vítimas do passado e pela reparação do abandono e privações sofridas.

Por fim, a exclusão que os velhos vivem no capitalismo flexível expressa um conjunto de experiências de possibilidades interrompidas. As experiências dos velhos oprimidos no capitalismo flexível narradas por Bosi remetem à imagem que Benjamin (2012c) alude do Angelus Noevus para indicar a necessidade de impedir o curso catastrófico do progresso em todos os níveis de opressão e violência que carrega desde o início do capitalismo, diz: 
Há um quadro de Klee que se chama Angelus Novus. Representa um anjo que parece querer afastar-se de algo que ele encara fixamente. Seus olhos estão escancarados, sua boca dilatada, suas asas abertas. O anjo da história deve ter esse aspecto. Seu rosto está dirigido para o passado. Onde nós vemos uma cadeia de acontecimentos, ele vê uma catástrofe única, que acumula incansavelmente ruína sobre ruína e as dispersa a nossos pés. Ele gostaria de deter-se para acordar os mortos e juntar os fragmentos. Mas uma tempestade sopra do paraíso e prende-se em suas asas com tanta força que ele não pode mais fechá-las. Essa tempestade o impele irresistivelmente para o futuro, ao qual ele vira as costas, enquanto o amontoado de ruínas cresce até o céu. Essa tempestade é o que chamamos progresso. (Benjamin, 2012c, p. 245)

\section{Notas}

1 Ao narrar suas lembranças, reconstrói não só a história individual, mas parte da história da própria cidade de São Paulo no processo de modernização.

2 Cinco dos entrevistados tiveram que trabalhar desde a infância: "O sr. Amadeu foi metalúrgico, o sr. Ariosto garçom e florista, d. Alice costureira, d. Risoleta cozinheira, para mencionar apenas as ocupações principais de cada um.” (Bosi, 1994, p. 454)

\section{Referências}

Benjamin, W. (2012a). Sobre o conceito da história. In Magia e técnica, arte e política: ensaios sobre literatura e história da cultura (Vol. 1, $8^{a}$ ed., pp. 241-252). São Paulo: Brasiliense.

Benjamin, W. (2021b). O narrador: considerações sobre a obra de Nikolai Leskov. In Magia e técnica, arte e política: ensaios sobre literatura e história da cultura (Vol.1, $8^{\mathrm{a}}$ ed., pp. 213-241). São Paulo: Brasiliense.

Benjamin, W. (2012c). Experiência e Pobreza. (2012c). In Magia e técnica, arte e política: ensaios sobre literatura e história da cultura (Vol. 1, $8^{a}$ ed., pp. 123-128). São Paulo: Brasiliense.

Bosi, E. (1994). Memória e sociedade: Lembranças dos velhos. São Paulo: Companhia das Letras.

Freud, S. (1914/1996). Recordar, Repetir e Elaborar (Novas Recomendações Sobre a Técnica da Psicanálise II). In Caso Schreber, Artigos sobre Técnica e outros trabalhos (Vol. XII, pp. 161171). Rio de Janeiro: Imago.

Gagnebin, J. M. (2012). Walter Benjamin ou a história aberta. In Magia e técnica, arte e política: ensaios sobre literatura e história da cultura (Vol. 1, $8^{a}$ ed., pp. 7-20). São Paulo: Brasiliense.

Löwy, M. (2005). Walter Benjamin: aviso de incêndio - Uma leitura das teses "Sobre o conceito de História". São Paulo: Boitempo. 


\section{LARISSA LEÃO DE CASTRO}

https://orcid.org/0000-0001-5187-913X

Doutoranda em Psicologia Clínica e Cultura pela Universidade de Brasília (UNB).

Endereço: Pós-Graduação em Psicologia Clínica e Cultura (PPGPsiCC).

Campus Universitário Darcy Ribeiro, Brasília-DF, CEP 70910-900

E-mail: larissa.leao.castro@gmail.com

\begin{tabular}{|c|c|}
\hline Histórico & $\begin{array}{l}\text { Submissão: 09/04/2019 } \\
\text { Aceite: 01/04/2020 }\end{array}$ \\
\hline $\begin{array}{l}\text { Consentimento } \\
\text { de uso de imagem }\end{array}$ & Não se aplica. \\
\hline $\begin{array}{l}\text { Aprovação, ética } \\
\text { e consentimento }\end{array}$ & Não se aplica. \\
\hline Financiamento & $\begin{array}{l}\text { O presente trabalho agradece o auxílio financeiro à pesquisa de doutorado } \\
\text { pelo Conselho Nacional de Desenvolvimento Científico e Tecnológico } \\
\text { (CNPq), órgão público federal que contribui para a dedicação dos } \\
\text { pesquisadores do país à pesquisa voltada para o interesse coletivo da } \\
\text { população brasileira. }\end{array}$ \\
\hline
\end{tabular}

